\title{
Acute toxicity and damage of tissue from benzothiazole-based ionic liquids in zebrafish(Danio rerio)
}

\author{
Yanwen Chen ${ }^{1, a}$, Caiyun Xie ${ }^{2, b}$, Yingjie Luo ${ }^{1, c}$, Shun Yao ${ }^{1 d}$,Hang Song ${ }^{1 *}$ \\ ${ }^{1}$ Department of pharmaceutical and Biological Engineering, Sichuan University, Chengdu 610065, \\ China;
${ }^{2}$ College of Architecture and Environment, Sichuan University, Chengdu 610065, China
a289481403@qq.com, bshanwen_xcy@126.com, ‘460443617@qq.com, \\ dyoungsun9802@163.com, ${ }^{* h a n g s o n g @ v i p . s i n a . c o m ~}$
}

\begin{abstract}
Keywords: ILs; Toxicity; Histological observations
Abstract. Ionic liquids (IL) have attracted recent more attention to consider adverse impact on living organisms and ecosystems. This study used took zebrafish as an aquatic living model for investigating the acute toxicity of benzothiazole-based ILs on fish. Zebrafish were exposed to five different concentrations of four neutral and one acidic IL solutions respectively for $24 \mathrm{~h}$. The $50 \%$ lethal concentration for each the IL was calculated. The treated zebrafish samples were further dissected for preliminary histological examination. It indicated the long-chain of cation ILs were more toxic than the short-chain ones and the acidic ILs are more toxic than the neutral ILs to superficial and internal organs of zebrafish.
\end{abstract}

\section{Introduction}

Ionic liquids (ILs) are considered to be green solvents and used in catalysis, electrochemistry, extraction separation as materials due to good applicable property ${ }^{[1-5]}$. Therefore ILs are superior to traditional solvents and have been considered as a path way to environment acceptability ${ }^{[3,6,7]}$. But the ILs of chemical stability and less volatile could accumulate in water environment, instead of the atmosphere, to lead to certain damage to living organisms and ecosystem ${ }^{[8,9]}$. It has been found recently that some ILs are potentially toxic because of their structure and raw organic material in synthesis process. This study concentrates on the acute toxicity of ILs including the effects on behavior and histological damage ${ }^{[10,11]}$. a series of benzothiazole-based novel ILs (BthILs) were developed and demonstrated potential applications in catalysis and extraction separation ${ }^{[12,13]}$, as experimental subject. Present study selected some of the ILs including four neutral ILs such as $\left[\mathrm{C}_{2} \mathrm{Bth}\right][\mathrm{Br}],\left[\mathrm{C}_{3} \mathrm{Bth}\right][\mathrm{Br}],\left[\mathrm{C}_{4} \mathrm{Bth}\right][\mathrm{Br}],\left[\mathrm{C}_{5} \mathrm{Bth}\right][\mathrm{Br}]$ and one acidic $[\mathrm{HBth}][\mathrm{Br}]$ for investigating the regular acute toxicity in aquatic environment. Zerbrafish are sensitive to environmental change ${ }^{[14,15]}$ and most widely used as good research object model to test the effects of heavy metal salts, sewage and radioactive substance on human ${ }^{[16,17]}$. For evaluating the biological toxicity and aquatic environmental impact of BthILs, this study conducted acute toxicity and damage of tissue test ${ }^{[18,19]}$. The toxicities of benzothiazole-based ILs on the gills, fins, and intestines of zebrafish were investigated to assess the acute toxicity effects in certain ILs concentration.

\section{Materials and methods}

\section{Materials}

The ILs were prepared as preciously study ${ }^{[20]}$. The chemicals for ILs synthesis were purchased from Kelong (Chengdu, China) and of analytical grade. Zebrafish, purchased from Chengdu Aquarium Fishery, China, were assessed healthy. The each batch were raised in $20 \mathrm{~L}$ fish tank for 1 week and the death rate must below $10 \%$ under the condition of laboratory of $\mathrm{pH}=7.4 \pm 0.2,16 \pm 1^{\circ} \mathrm{C}$. During period above, the fish were fed every two days, controlled $12 \mathrm{~h} \mathrm{light} / 12 \mathrm{~h}$ dark $^{[11]}$. Finally, the fish must have been fasted for $24 \mathrm{~h}$ before beginning of test. 
Acute toxicity testing \& sampling

The preliminary methods were conducted according to reported procedure ${ }^{[21]}$ with some modification $^{[22]}$ to acquire the $50 \%$ lethal concentration (LC50) after $24 \mathrm{~h}$ of exposure in fish. After the preliminary experiment, 20 healthy zebrafish were selected as a group placed in $10 \mathrm{~L}$ solution and then their behavior were observed without feeding during the $24 \mathrm{~h}$ period of acute toxicity test ( $\mathrm{n}=3$ with 3 pools ). It was needed to observe the behavior of zebrafish and the dead data were counted up and related death rates were calculated when the experiment period end. At the end of the experiment, it should be calculated the death rate with the analysis of died cases, and used the linear regression method[30] to get the $\mathrm{LC}_{50}$.

Histological observation

After $24 \mathrm{~h}$ of exposure to ILs solution, the zebrafish samples were dissected for histological observations. Their gill, dorsal fins and intestine were isolated for observing and the observations were compared with those of control fish.

\section{Results and Discussion}

Acute toxicity

According to Test Method of Fish Acute Toxicity for Dangerous (GB/T 21281-2007) and International Organization for Standardization (ISO), it was considered to be super virulent when the $50 \%$ lethal concentration ( $\mathrm{LC}_{50}$ ) of sample solution $<50 \mathrm{mg} / \mathrm{L}$ and hypotoxicity when $\mathrm{LC}_{50}$ of sample solution was beyond $100 \mathrm{mg} / \mathrm{L}$. Therefore it was necessary to consider that zebrafish's lethal data from $10 \mathrm{mg} / \mathrm{L}$ to $300 \mathrm{mg} / \mathrm{L}$ of 5 kinds of BthILs for $\mathrm{LC}_{50}$ test. The acute toxicity were all taken place in IL solution, $\mathrm{pH} \approx 7$, shown in Table 1.

Table 1 The $\mathrm{LC}_{50}$ of 5 types of BthILs on acute toxicity of zebra fish

\begin{tabular}{lll}
\hline ILs & Zebrafish $\left(\mathrm{LC}_{50} / 24 \mathrm{~h}\right)$ & Toxicity grade \\
\hline$\left[\mathrm{C}_{2} \mathrm{Bth}\right][\mathrm{Br}]$ & $413.96 \mathrm{mg} / \mathrm{L} \pm 0.5 \mathrm{mg} / \mathrm{L}$ & low \\
{$\left[\mathrm{C}_{3} \mathrm{Bth}\right][\mathrm{Br}]$} & $203.98 \mathrm{mg} / \mathrm{L} \pm 0.3 \mathrm{mg} / \mathrm{L}$ & low \\
{$\left[\mathrm{C}_{4} \mathrm{Bth}\right][\mathrm{Br}]$} & $166.7 \mathrm{mg} / \mathrm{L} \pm 8.8 \mathrm{mg} / \mathrm{L}$ & low \\
{$\left[\mathrm{C}_{5} \mathrm{Bth}\right][\mathrm{Br}]$} & $74.77 \mathrm{mg} / \mathrm{L} \pm 1.2 \mathrm{mg} / \mathrm{L}$ & medium \\
{$[\mathrm{HBth}][\mathrm{Br}]$} & $31.3 \mathrm{mg} / \mathrm{L} \pm 1.1 \mathrm{mg} / \mathrm{L}$ & medium \\
\hline
\end{tabular}

The results from table.1 suggested that the toxic effect of ILs having same anion varied with different cationic structures and the toxicity enhanced with the length of alkyl chain. It were considered that the alkylation effect from longer alkyl structure produced more toxic effect on zebrafish. Otherwise the toxicity of acidic BthILs was higher than neutral. The [HBth][Br] of the same anion Br- presented high acid and corrosion to zebrafish. The toxicity grade of acidic ILs was higher, while that of the neutral $[\mathrm{CnBth}][\mathrm{Br}](\mathrm{n}=2,3,4,5)$ were lower. So the safety of neutral ILs $[\mathrm{CnBth}][\mathrm{Br}](\mathrm{n}=2,3,4,5)$ were much better than the acid ILs.

3.2 Histological changes of toxic effects

The tissue samples were taken from the zebrafish which were exposed to the aqueous solution of $20 \mathrm{mg} / \mathrm{L}$ [HBth] $[\mathrm{Br}]$ and control group respectively. After exposed to $24 \mathrm{~h}$, the $\mathrm{pH}$ was maintained at $6 \sim 7$, and then the tissue samples were taken to be observed about the damage in gill, fins and intestines of the fish from each group.

From the Fig.1-a, the gill's edge had fallen off and color was dark after exposing to acid ILs directly, whereas the sample of control group remained intact shape. It is suggested the ILs have apparently corrosive effect to the gill.

Due to the balanced function of fins, it was inferred to the damage of fins related to sluggish behavior of fish. The sample of control group had intact skeleton, distinct lines and perfect edge (Fig.2-a). The 
tested fish exposed to $20 \mathrm{mg} / \mathrm{L}$ [HBth][Br] solution showed blurry edge and damaged skeleton structure (Fig.2-b).

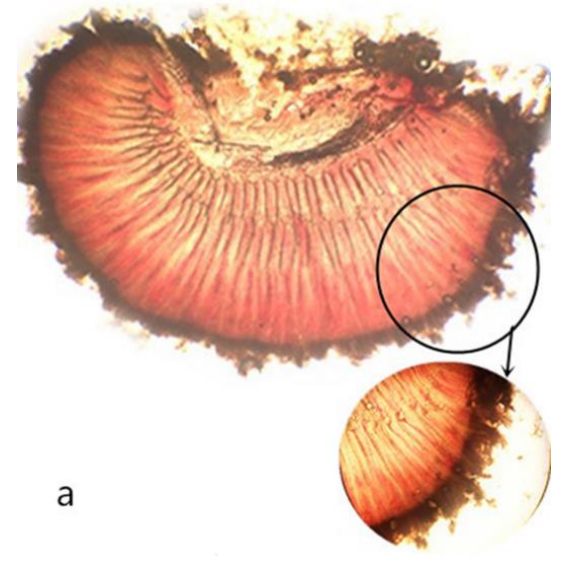

(a) Control group;

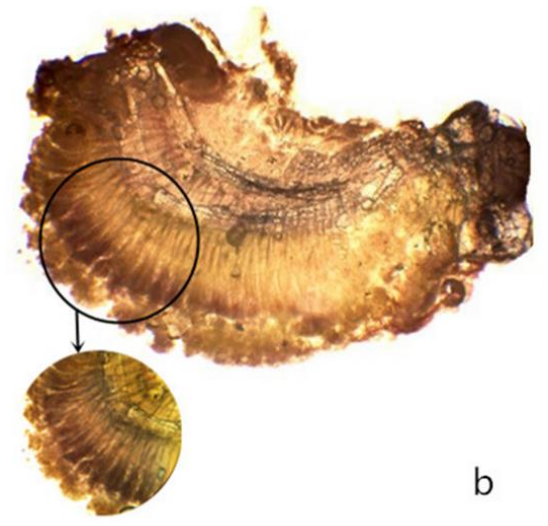

(b) $20 \mathrm{mg} / \mathrm{L}[\mathrm{HBth}][\mathrm{Br}]$

Fig.1 The micrograph on the gill of zebrafish magnified for 40 times:
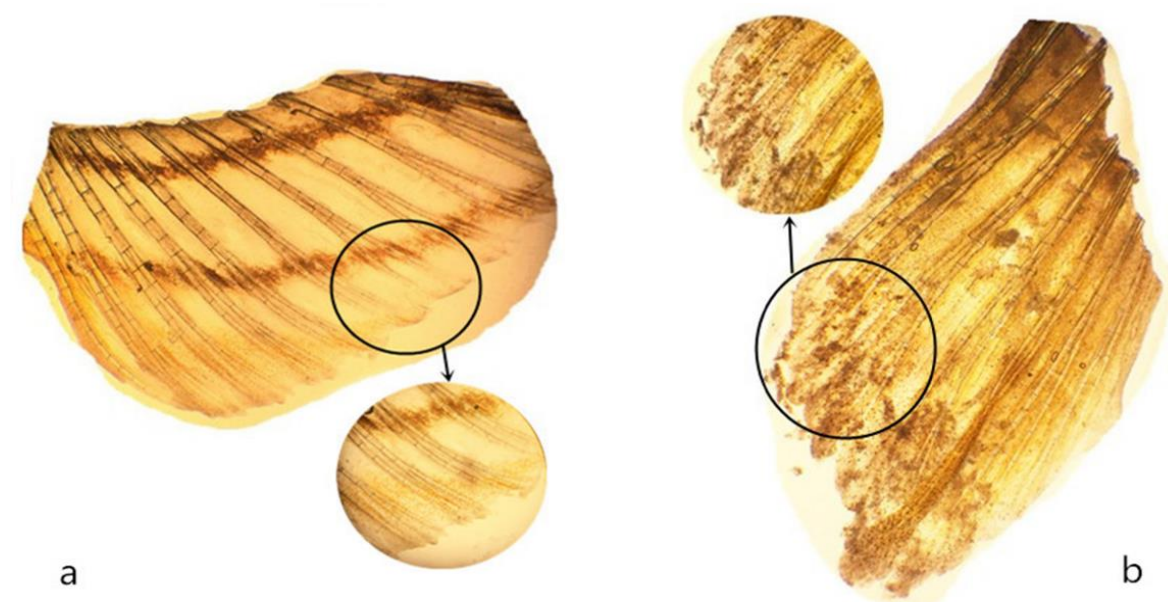

(a)Control group; (b)20mg/L[HBth][Br]

Fig.2 The micrograph on the fins of zebrafish magnified for 40 times
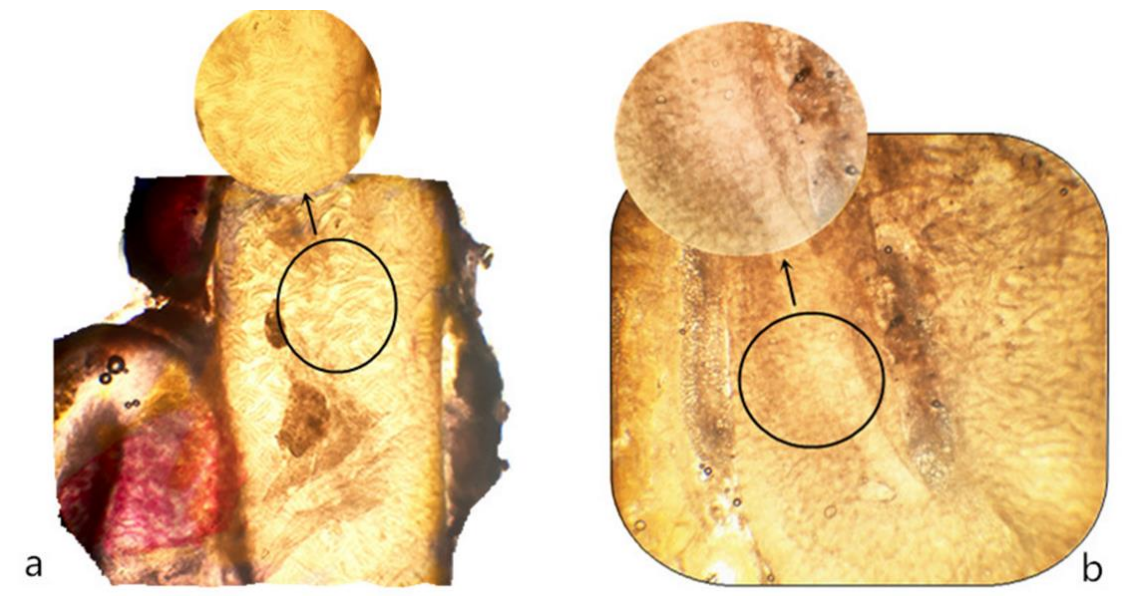

Moreover, the intestinal wall tissue of control group had perfect structure and clear wrinkle from Fig.3-a, whereas the section from the fish exposed to $20 \mathrm{mg} / \mathrm{L}$ [HBth][Br] solution was observed to corrosion of intestine and damage wrinkle (Fig. 3-b).
(a)Control group;
(b) $20 \mathrm{mg} / \mathrm{L}[\mathrm{HBth}][\mathrm{Br}]$

Fig.3 The micrograph on the intestine of zebrafish magnified for 40 times 
Intestine has function of the digestion and metabolism for fish, and damage of epidermal structure of intestine meant that ILs had entered into and impacted on various metabolic reaction. Thus it was observed the metabolism of fish revved up for toxin discharge.

\section{Conclusion}

The benzothiazole-based ILs exhibited toxicity to zebrafish through certain lethal concentration. This results and the acute toxicity test suggest that acid ILs have higher deadly toxicity at macroscopical level, and neutral ILs take more serious impact on internal enzyme activity from micro perspective. In a word, the BthILs have certain toxic effect to contaminate the water and cause the death of organism.

\section{Acknowledgments}

This study was financially supported by the National Scientific Foundation of China (No. 81373284).

\section{References}

[1]K.M Docherty, Green Chem 2005, 7, 185.

[2]D Ajloo, M Sangian, M Ghadamgahi, M Evini, A.A Saboury, Int. J. Biol. Macromol 2013, 55, 47.

[3]T Liu, L.S Zhu , H Xie, J.H Wang , J Wang, F.X Sun, F.H Wang, Environ. Sci. Pollut. Res.2013, 21(5), 3936.

[4]J Ranke, S Stolte, R Stoermann, J Arning,B Jastorff, Chem.Rev. 2007. 107(6),2183.

[5]A Romero, A Santos, J Tojo, A Rodriguez, J Hazard Mater 2008, 151,268.

[6]J.D Holbrey, R.D Rogers, IONIC LIQUIDS: INDUSTRIAL APPLICATIONS FOR GREEN CHEMISTRY 2009, 446.

[7]M Petkovic, K.R Seddon, L.P.N Rebelo, C.S Pereira, Chem.Soc.Rev. 2011, 40(3),1383.

[8]R.D Rogers, K.R Seddon, Acs Symposium 2002.

[9]A Latała, P Stepnowski, M Nedzi, W Mrozi, Aquat. Toxicol. 2005, 73, 91.

[10]M Matzke, S Stolte, K Thiele, T Juffernholz, J Arning, J Ranke, U.W Biermannd, B Jastorffb, Green Chem 2007, 9(11),1198.

[11]M Diekmann, P Waldmann, A Schnurstein, T Grummt, T Braunbeck, R Nagel, Aquat .Toxicol. 2004, 68, 27.

[12]W.F Luo, S Yao, J.B Liu, X.S Zhou, H Song, West China Journal of Pharmaceutical Sciences 2012,27(1),61.

[13]J.L Du, H.Y He, Y Zhou, D.S Song, Z.J He, S.Y Cui, Applied. Chem. Ind. 2015, 44(12),2343..

[14]J Pérez, I Domingues, M Monteiro, AMVM Soares,S Loureiro, Environ. Sci. Pollut. R.2013, 20(7),4671.

[15]Z.P Liu, S.L Zhang, J.H Yang, R Tang, B.J Li, Environ. Sci. Technol. 2011.

[16]H. J Jeon, Y. H Lee, M. J Kim, S. D Choi, B. J Park, S. E Lee, Environ. Toxicol. Pharm 2016, 43, 166.

[17]C Pretti, C Chiappe, D Pieraccini, M Gregori, F Abramo, G Monni, L Intorre, Green Chem 2006,8, 238.

[18]P. C. A. G Pinto, A. D. F Costa, J. L. F. C Lima, M. L. M. F. S Saraiva, Chemosphere 2011, 82(11), 1620.

[19]Y Wang, M Radosevich, D Hayes, L Nicole, Biotechnol. Bioeng.2011,108 (5), 1042.

[20]Q Peng, Y. W Zhang, X. M Wang, Z. D Wang, S Yao, H Song, Chinese Journal of Synthetic Chemistry 2012.

[21]X. Y Li, S. H Zeng, W. H Zhang, L Liu, S Ma, J. J Wang, Environ. Toxicol.2013, 28(4), 207.

[22]X Zhang, Y.G Liu, Beijing Medical University China Xiehe Medical University Press: Beijing. pp 1997, 211. 